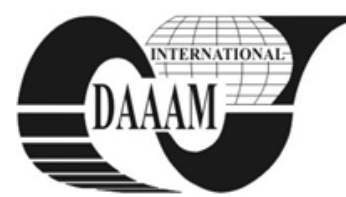

Annals of DAAAM for 2011 \& Proceedings of the 22nd International DAAAM Symposium, Volume 22, No. 1, ISSN 1726-9679 ISBN 978-3-901509-83-4, Editor B. Katalinic, Published by DAAAM International, Vienna, Austria, EU, 2011 Make Harmony between Technology and Nature, and Your Mind will Fly Free as a Bird

Annals \& Proceedings of DAAAM International 2011

\title{
THE RULE-BASED APPROACH IN STUDYING THE INFLUENCE OF A DIFFERENT TEXTILE SURFACES ON COLOUR SIMILARITY
}

\author{
GLOGAR, M[artinia] I[ra]; PARAC - OSTERMAN, D[jurdjica]; \\ GRUNDLER, D[arko] \& ROLICH, T[omislav]
}

\begin{abstract}
In this work the approach are based exactly on surface - structural characteristics of textile samples and the main idea was to examine the approach using fuzzy logic based technique in order to provide the method that would include surface parameters of textile samples that are of importance in colour applying on a different structured textile surfaces The results obtained confirms the possibility of using the linguistic form of fuzzy logic that allows any subjective as well as objective parameter to be processed, which is of significant importance in studying the influence of textile surface structure parameters on colour appearance.
\end{abstract}

Key words: CMP system, fuzzy logic, colour difference, surface structure influence

\section{INTRODUCTION}

As textile is a highly heterogeneous in its structure, it is often a difficult task to achieve the satisfactory colour similarity on the different structured textile materials. In literature the number of reports about modelling the colour appearance of structured materials can be found (Joaneli et al, 2006; Tominaga, 1996; Tsoutseos \& Nobbs, 2000). One of the most unconventional approaches was made by Allen and Goldfinger (Tsoutseos \& Nobbs, 2000). The modern approach to improved colour matching is through application of fuzzy logic system in aim of achieving the advanced way of observing the influences of surface structure to colour similarity. It is a rule - based approach which is tolerant of imprecise data and any set of input-output data can be created as a fuzzy system (Cheetam, 1997; Bombardier et al, 2009; Bombardier et al, 2007). In this paper the fuzzy logic based approach was performed in studying the influence of a different textile surface structure on colour appearance and similarity. In this paper the results of an extensive study will be presented on a one, most indicative, case.

\section{APPROACH}

The two $100 \%$ cotton knitted samples were chosen for the analysis.

\begin{tabular}{|l|l|}
\hline Horizontal density $\mathrm{D}_{\mathrm{h}}$ & 11.60 stitches $/ \mathrm{cm}$ \\
\hline Vertical density $\quad \mathrm{D}_{\mathrm{v}}$ & 14.00 stitches $/ \mathrm{cm}$ \\
\hline Thickness & $0.956 \mathrm{~mm}$ \\
\hline Mass per $\mathrm{m}^{2}$ & $283 \mathrm{~g} / \mathrm{m}^{2}$ \\
\hline Yarn fineness & $\begin{array}{l}\text { basally fibre }-24 \text { tex (front side) } \\
\text { coating fibre }-59 \text { tex (back side) }\end{array}$ \\
\hline
\end{tabular}

Tab. 1. Characteristics of chosen textile samples

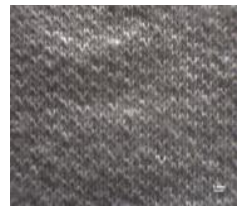

Sample 1

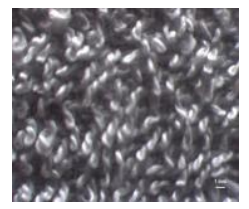

Sample 2
Fig. 1. CCD Digital camera scans of samples
The constructional characteristics of the two samples are identical (Tab. 1), but since the samples were made in a different process of knitting, they have significant difference in a surface structure (Fig.1). First the both samples were dyed in four basic concentrations of dyestuff: $0.25 \%, 0.75 \%, 1.4 \%$ and $2 \%$. Afterward, samples were measured spectrophotometrically and the K/S values were compared in order to establish is there any difference in equally dyed samples regarding the specific surface structure. Further, the sample 1 was chosen as the standard (reference sample). Its data, obtained by the spectrophotometer measurement, were stored in a computer database and were used as the reference data in a further work. The computer matching (CMP) on sample 2 according to reference sample was performed, for determining the suitable concentration of dyestuff in relation to specific surface spectral characteristics of sample 2. A yellow shaded direct dyestuff suitable for cotton dyeing commercially named Tubantin Yellow 3R was used in experimental work. For usage of this technique the computer database of spectrophotometer data for chosen dyestuff and for each type of substrate used in the experimental work are required. The fuzzy logic system was constructed using MATLAB and Fuzzy Logic Toolbox. Fuzzy logic system was created with the input space based on terms that would define the surface characteristics of samples and through the set of rules, provide the output space which would be the change of dyestuff concentration in dependence of the characteristics defined for one chosen sample. The structure of the input space created based on five linguistic variables defined as thickness, roughness, gloss, thread density and the dyestuff concentration and the output space is shown on Fig. 2 .

For each linguistic value the membership function was determined. The degree to which the inputs belong to each of the appropriate fuzzy sets is determined via membership functions. Three built-in membership functions were used (smf, $\mathrm{zmf}$ and pimf). Its graphs are given in Fig. 3.

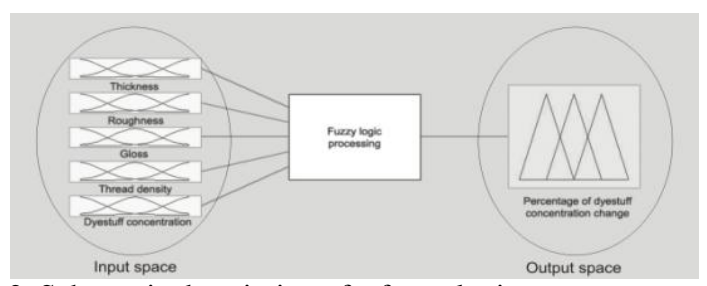

Fig. 2. Schematic description of a fuzzy logic system
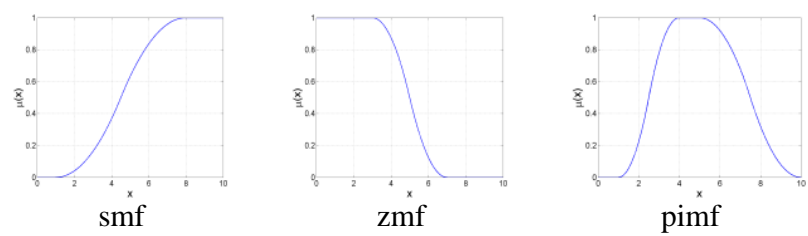

Fig. 3. smf membership function with parameters $a=1$ and $b=8$; zmf membership function with parameters $a=3$ and $b=7$; pimf membership function with parameters $a=1, b=4, c=5$ and $d=9$ is shown 
60 if-then rules were created following the example: If thickness is low and roughness is middle and gloss is low and thread density is low and dyestuff concentration is very low then change of basic dyestuff concentration is middle. For the implication the two built-in methods from Fuzzy Logic Toolbox are supported: min (minimum) and prod (product). In this paper the min methods for implication is used. The min method for AND operator and max method for OR operator were used and also the max method for aggregation was used. For deffuzification the centroid method was used. These 60 ifthen rules were defined based on experimental knowledge.

\section{RESULTS AND DISCUSSION}

For samples composed of the same materials variances may be seen in colour due to differences in a smoothness or gloss of the surface. Colour of textile surfaces may appear different if the surface conditions are changed, because the amount of specular reflectance and diffused reflectance changes. Since the human eye view only the diffused light, it is expected that, for the viewer, the differences in surface quality will influence the difference appearance of colour. So it can be said, that because of certain subjective elements, human eye recognized the changes in surface as the changes in colour. In this paper the aim was to find a way of including this subjective elements that influence the colour appearance into a studying the colour matching.

Observing the results of samples dyed in four basic concentrations through $\mathrm{K} / \mathrm{S}$ value (Fig. 6), it can be seen that the surface of sample 1 (smoother surface) produce lower K/S value of the same amount of dyestuff, as the result of the higher reflectance from the smoother surface. It is in correlation with the K/S value obtained higher for sample 2 (rougher surface) which confirm the influence of surface structure on appearance of colour and showed that the rougher surface, even equally coloured, will perform deeper colour. Based on results, which indicate the necessity of a dyestuff concentration correction (Fig. 6), the "CMP" procedure was performed. For sample 2 the dyestuff concentration correction was performed based on the reference sample data (sample 1) stored in database. The corrected concentrations are shown in Tab. 5.

The final step in the experimental work was to test the fuzzy logic system. The fuzzy logic system does not give any answer on colour, but shows how, based on set of rules, to make the correction in dependence on different surface structures.

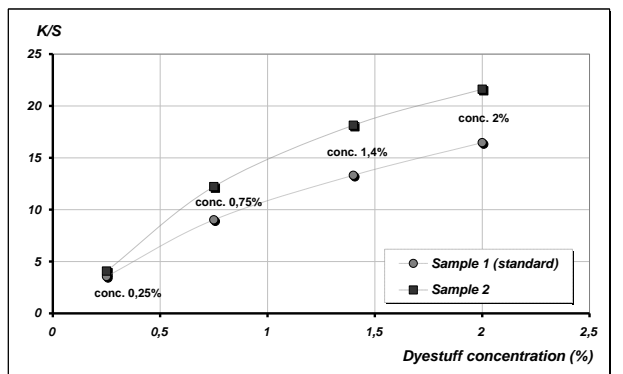

Fig. 6. K/S vs. concentration relationship for tested sample

\begin{tabular}{|c|c|c|c|c|}
\hline $\begin{array}{l}\text { Basic dyestuff } \\
\text { concentrations (\%) }\end{array}$ & 0.25 & 0.75 & 1.4 & 2 \\
\hline \multicolumn{5}{|c|}{ New concentrations obtained by the CMP operation } \\
\hline Sample 2 & $0.22 \%$ & $0.68 \%$ & $1.25 \%$ & $1.53 \%$ \\
\hline \multicolumn{5}{|c|}{ New concentrations obtained by Fuzzy logic system } \\
\hline Sample 2 & $0.165 \%$ & $0.69 \%$ & $1.21 \%$ & $1.50 \%$ \\
\hline
\end{tabular}

The output variable providing the results of concentration change is shown in Tab. 5. The textile samples were dyed in obtained concentrations and spectrofotometrically measured afterwards. The values of colour parameters obtained for sample 2, dyed in corrected concentration obtained by CMP and Fuzzy system, were compared to colour parameter values of sample 1 (reference sample) and the colour difference values $\left(\mathrm{dE}_{\mathrm{CMC}}\right)$ were calculated (Fig. 7.).

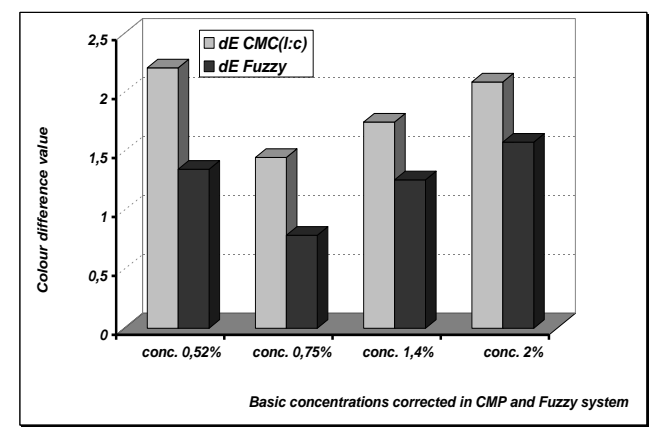

Fig. 7. Colour difference values obtained for sample 2 compared to reference sample 1 , for four basic dyestuff concentrations corrected in CMP and Fuzzy system

The colour differences $\left(\mathrm{dE}_{\mathrm{CMC}}\right)$ obtained for fuzzy logic system are lower and closer to value of 1 (in the range of agreed tolerances which is for textile set on $\mathrm{dE}_{\mathrm{CMC}} \leq 1$ ) comparing to those obtained with CMP system. The results obtained confirms the possibility of using the linguistic form of fuzzy logic that allows any subjective as well as objective parameter to be processed, which is of significant importance in studying the influence of textile surface structure parameters on colour appearance.

\section{CONCLUSION}

The possibility of fuzzy logic based reasoning application is confirmed, but further study of the subject is necessary with detailed analyze of a fuzzy logic rule construction. The results obtained confirmed that the fuzzy based system can react on change of surface structure parameters, which is result of proper definition of rules and defined linguistic variables that use words for assigning values of properties that influence the experience of an observer (gloss, smoothness, roughness, etc.). But certain limitation of this procedure is that concrete fuzzy system is applicable only for this particular colour - yellow, and for each other colour, separate fuzzy system should be constructed. Also it requires a lot of experimental knowledge and experience. The analysis and the results shown in this paper are the preliminary part of a research but they indicate the further research since it has been confirmed that fuzzy based system can be applied for surface structure influence evaluation.

\section{REFERENCES}

Bombardier, V.; Mazaud, C.; Lhoste, R.; Vogrig, R. (2007). Contribution of Fuzzy Reasoning Method to Knowledge Integration in a Wood Defect Recognition System, Computers in Industry Journal, Vol. 58, 355 - 366.

Bombardier, V.; Schmitt, E.; Charpentier, P. (2009). A Fuzzy Sensor for Color Matching Vision System, Measurement, Vol. 42, $189-201$

Cheetam, W.; Graf, J. (1997). Case - Based Reasoning in Color Matching, Case - Based Reasoning Research and Development, Leake, D., B \& Plaza, E. Eds., Berlin, Springer Verlag

Joaneli, M. I.; Parac - Osterman, Đ \& Golob, D. (2006). Textile Surface Structure Importance and Kubelka - Munk Theory in Colour Match Calculations, Colourage, Vol.53, No. 4., ISSN: $0010-1826-59-67$

Tsoutseos, A. A.; Nobbs, J. H. (2000). Alternative Approach to Colour Appearance of Textile Materials with Application to the Wet/Dry Reflectance Prediction, Textile Chemists and Colourists \& American Dyestuff Reporter, Vol. 32, No. 6, ISSN 0040-490X 